\title{
Effects of curing protocol and storage time on the micro-hardness of resin cements used to lute fiber-reinforced resin posts
}

\author{
Marcelo Barbosa RAMOS', Thiago Amadei PEGORARO², Luiz Fernando PEGORARO³, Ricardo Marins CARVALHO ${ }^{4}$ \\ 1- PhD student, Bauru School of Dentistry, University of São Paulo, Bauru, SP, Brazil; Health Sciences Center, University of Fortaleza, Fortaleza, CE, Brazil. \\ 2- DDS, PhD, Health Science Center, University of the Sacred Heart, Bauru, SP, Brazil. \\ 3- DDS, PhD, Department of Prosthodontics, Bauru School of Dentistry, University of São Paulo, Bauru, SP, Brazil. \\ 4- PhD, School of Dentistry, Canada Director for Research, Vancouver, BC, Canada.
}

Corresponding address: Marcelo Barbosa Ramos - Department of Prosthodontics - Bauru School of Dentistry, University of São Paulo - Al. Octávio P. Brisola 9-75, Bauru - São Paulo - 17012-901 - Brasil - Phone: +55 (14) 3235-8277 - e-mail: marcelobr74@yahoo.com.br.

Received: January 13, 2012 - Modification: August 16, 2012 - Accepted: September 14, 2012

\section{ABSTRACT}

$\mathrm{O}$ bjectives: To determine the micro-hardness profile of two dual cure resin cements (RelyX - U100 ${ }^{\circledR}, 3 \mathrm{M}-\mathrm{ESPE}$ and Panavia $\mathrm{F} 2.0^{\circledR}$, Kuraray) used for cementing fiberreinforced resin posts (Fibrekor ${ }^{\circledR}$ - Jeneric Pentron) under three different curing protocols and two water storage times. Material and methods: Sixty $16 \mathrm{~mm}$ long bovine incisor roots were endodontically treated and prepared for cementation of the Fibrekor posts. The cements were mixed as instructed, dispensed in the canal, the posts were seated and the curing performed as follows: a) no light activation; b) light-activation immediately after seating the post, and; c) light-activation delayed 5 minutes after seating the post. The teeth were stored in water and retrieved for analysis after 7 days and 3 months. The roots were longitudinally sectioned and the microhardness was determined at the cervical, middle and apical regions along the cement line. The data was analyzed by the three-way ANOVA test (curing mode, storage time and thirds) for each cement. The Tukey test was used for the post-hoc analysis. Results: Light-activation resulted in a significant increase in the microhardness. This was more evident for the cervical region and for the Panavia cement. Storage in water for 3 months caused a reduction of the micro-hardness for both cements. The U100 cement showed less variation in the micro-hardness regardless of the curing protocol and storage time. Conclusions: The micro-hardness of the cements was affected by the curing and storage variables and were material-dependent.

Key words: Resin cements. Adhesive cementation. Light curing. Dental adhesives.

\section{INTRODUCTION}

Adhesive cementation of intra-radicular posts is a highly sensitive procedure ${ }^{10}$ subjected to technical difficulties that begin during the creation of the post space and involve several operative steps up to the final polymerization of the cement ${ }^{26}$. The advantages are mostly due to their low solubility, superior mechanical and adhesive properties ${ }^{30}$. However, intra-radicular adhesive cementation still presents a significant challenge to clinicians due to the technical variables involved and little knowledge about the clinical predictability of these materials in the long term. Furthermore, resin cements undergo polymerization shrinkage that results in de-bonding tensions and gap formations along the canal walls ${ }^{9}$. Ultimately, light-activation does not reach beyond the cervical cuff and curing remains questionable along the root towards the apice ${ }^{19,21}$. To compensate this limitation, dual-cure resin cements have been developed with the hope that a chemical cure would provide maximum and uniform curing where light cannot reach. This, however, does not seem to be the case with all cements, as some are highly dependent on light energy to achieve adequate polymerization $3,9,27$.

Dual polymerization, the combination of light and chemical polymerization, provides a better 
conversion of monomers. This is important because inadequate polymerization is usually associated with the poor mechanical and biological properties of the resin cements ${ }^{13}$. Immediate light activation is recommended to set the cement, thus allowing the professional to perform subsequent clinical procedures without the need to wait for the chemical set to take place. However, it has been reported that immediate light activation stiffens the polymer chains and prevents the continuation of the chemical polymerization, thus causing an overall reduction in the degree of conversion with consequences to the material properties ${ }^{24}$.

The need for immediate light activation of dual cure cements has therefore been questioned as it could compromise chemical polymerization ${ }^{24,28}$. Some authors have suggested that the light activation should be delayed, so that chemical polymerization could progress further without being hindered by the stiffened light-cured chain. This could improve the overall degree of conversion and properties $^{23}$.

Ideally, resin cements should achieve their maximum cross-linking and degree of conversion to be able to withstand the intraoral challenges. A less than optimal cure has been related to increased water sorption 8,30 , which in turn causes a reduction of their mechanical properties, dissolving and leaching of some of the components, such as unreacted to degradation and erosion of the resin cement ${ }^{16}$. The micro-hardness test has been successfully used to evaluate the quality of the polymerization and the effects of water sorption on the resin materials ${ }^{4,11,15,26}$.

This study evaluated the changes in the microhardness of two resin cements used to lute fiberreinforced resin posts with modified, experimental curing protocols, along the cervical, middle and apical thirds. The micro-hardness measurements were taken after 7 days and 3 months of water storage. The null hypotheses tested were that: 1 ) the curing protocol would not affect the microhardness; 2) the micro-hardness would not vary along the root thirds, and; 3 ) water storage would not affect the micro-hardness.

\section{MATERIAL AND METHODS}

Sixty bovine incisors were transversally sectioned to remove the crowns and result in roots with $16 \mathrm{~mm}$ in length. The canals were instrumented with a\#25 K-file (Kerr Dental Manufacturing Co., Orange, CA, USA). The root canals were irrigated with $10 \mathrm{~mL}$ of $1.0 \% \mathrm{NaOCl}$ between each instrument change. The final irrigation was with $10 \mathrm{~mL}$ of $17 \%$ EDTA for 60 $\mathrm{sec}$, followed by $10 \mathrm{~mL}$ of $\mathrm{NaOCl}$ irrigation. The root canals were dried using paper points and obturated with gutta-percha (Endo Points, Paraíba do Sul, RJ,
Brazil). A size 40 gutta-percha cone was used as the master cone. The gutta-percha cones were coated with a calcium hydroxide-based cement (Sealer 26/ Dentsply, Rio de Janeiro, RJ, Brazil) before insertion into the canal by the lateral condensation technique and stored in water at $37^{\circ} \mathrm{C}$ until the preparation for post cementation (Figures $1 \mathrm{~A}-\mathrm{C}$ ). The post space was created with a $1.0 \mathrm{~mm}$ diameter $/ 13 \mathrm{~mm}$ long bur (Fibrekor bur, Pentron Clinical Technologies, LLC., Wallingford, CT, USA), followed by a 1.5 $\mathrm{mm}$ diameter bur (Fibrekor drill, Pentron Clinical Technologies, LLC., Wallingford, CT, USA), up to the length of $12 \mathrm{~mm}$ in order to standardize the cement line thickness at approximately $0.25 \mathrm{~mm}$ around the post. The fiberglass posts (Fibrekor, Pentron Clinical Technologies, LLC, Wallingford, CT, USA) were previously cleaned with $75 \%$ ethanol. Before the cementation, the canals were flushed with deionized water and dried with absorbent paper points. The cementation procedures were performed with two different dual-cure resin cements, Panavia F 2.0 (Kuraray Medical Inc. Kurashiki, Okayama, Japan) or RelyX U100 (3M ESPE, St. Paul, Minnesota, USA) (Figures $1 \mathrm{D}-\mathrm{F}$ and Figure 2). The mixed cements were applied on the post, which were then inserted into the canal. The excess cement was removed with a micro-brush.

For the cementation, the roots were randomly divided into 2 groups of 30 specimens per cement, and then further divided into 3 groups of 10 specimens according to the polymerization modes as follows: Group A (no light activation), Group B (immediate light activation) and Group C (delayed light activation for 5 minutes). The cements were light activated for $20 \mathrm{~s}$ (Optilight Plus, $420 \mathrm{~mW} /$ $\mathrm{cm}^{2}$, Gnatus Equip. Med. Odont., Ribeirão Preto, SP, Brazil) with the tip of the lamp placed at the post.

After completing the cementation, the specimens were stored in dark vials containing deionized water at $37^{\circ} \mathrm{C}$ (Figure $1 \mathrm{G}$ ). Five specimens from each group were retrieved after 7 days for testing (subgroup 1). The remaining specimens were kept under storage for 3 months (subgroup 2) and tested after that period. The water in the vials was replaced every 15 days during the storage period. Details of the cementation procedures are given in Figure 3.

\section{Root sectioning and micro-hardness measurements}

After retrieving from storage, the roots were longitudinally sectioned with a diamond disk (Wafering Diamond Blade - Extec, USA) in a serial cutting machine (Isomet 2000 Precision Saw Buehler, USA). The cut was made tangential to the post so that the cement line could later be exposed by sequential polishing. A second parallel cut was placed on the opposite external surface of the root to permit the seating of the specimen in the micro- 
hardness tester stage (Figure $1 \mathrm{H}$ ).

The exposed post surface was sequentially polished with 600-grit SiC abrasive paper for 3 minutes at a low speed and 1200-grit SiC abrasive paper for 5 minutes at a high speed, followed by felt paper and diamond paste for 5 minutes in a high speed under constant irrigation. Between each polishing step, the specimens were rinsed with deionized water for 30 seconds and ultrasonicated in deionized water for 2 minutes (Figure 1I-J).

The hardness tests were performed (Shimadzu Microdurometer Model HMV-2.000, Shimadzu Corporation, Japan) with a Knoop indenter under a static load of 50 grams for 10 seconds that was defined in the pilot test and based on other study ${ }^{26}$ (Figure $1 \mathrm{~K}$ ). Indentations were placed in the middle of the cement line, $1 \mathrm{~mm}$ apart from the cervical to apical third. The micro-hardness was calculated as the average value for each third. The first four indentations were assigned as the cervical third, the following four indentations were assigned as the middle third and the last four indentations were assigned as the apical third. The hardness was calculated and expressed as a Knoop hardness number ( $\mathrm{KHN}$ ) according to the following formula:

$$
H K=P / A=P / C_{p} \cdot L^{2}
$$
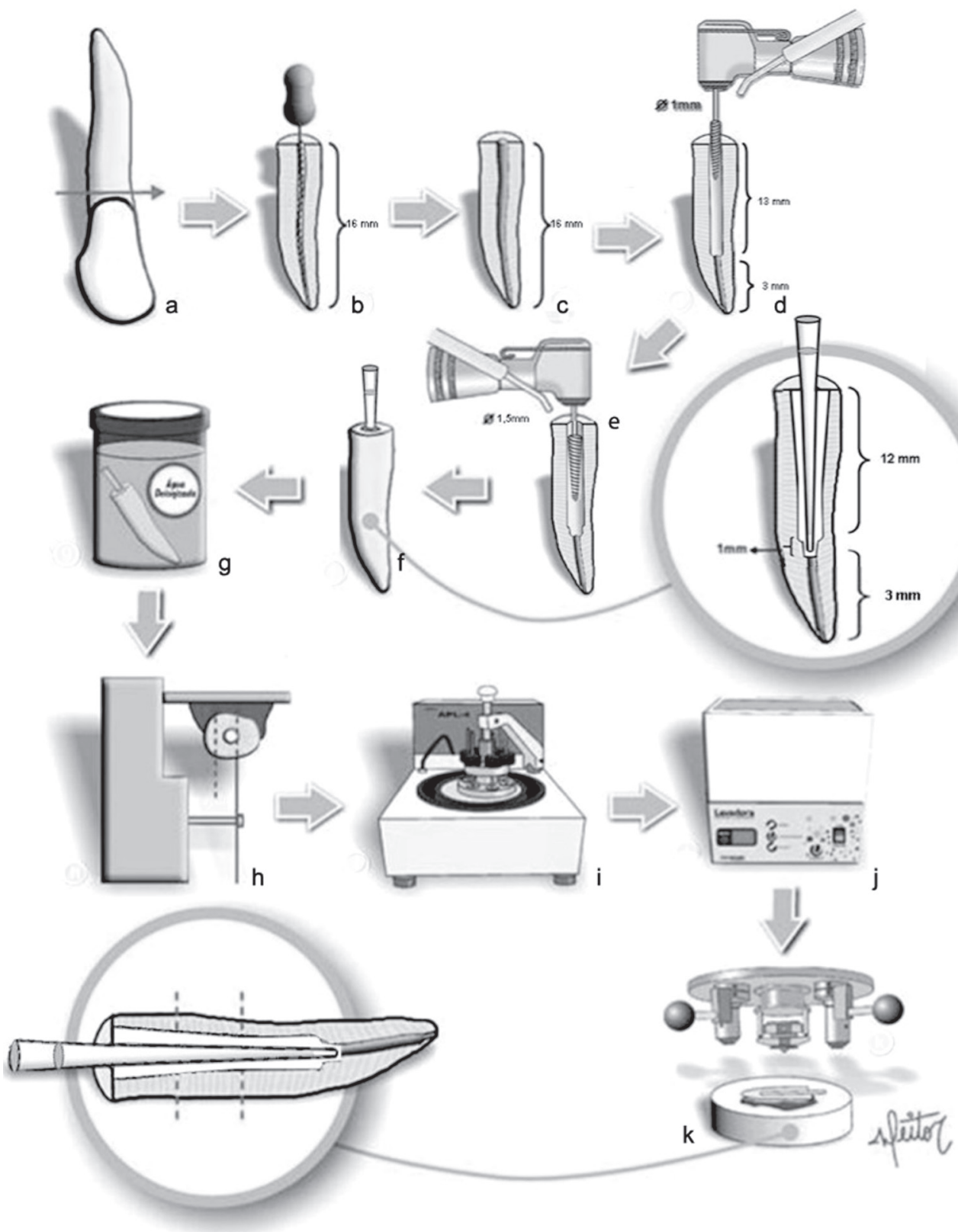

Figure 1- Schematic flow chart of the experimental steps: a: sectioning the bovine roots to the length of $16 \mathrm{~mm}$; $b$,c: endodontic treatment; $\mathrm{d}$ : post space preparation with $1 \mathrm{~mm}$-diameter bur to the length of $13 \mathrm{~mm}$; and e: enlargement of post space with $1.5 \mathrm{~mm}$-diameter bur to the length of $12 \mathrm{~mm}$; $\mathrm{f}$ : post cemented using either one of the cements; $\mathrm{g}$ : specimens stored in water for either 7 days or 3 months; h: root sectioning to expose the cement line; i: surface polishing for hardness measurements; j: ultrasound cleaning of specimens; $\mathrm{k}$ : microhardness indentations placed along the cement line 
Figure 2- Resin cements used in the study

\begin{tabular}{|c|c|c|c|}
\hline Cement* & Adhesive System* & Manufacturer & Lot \\
\hline PANAVIA F 2.0: & ED PRIMER A \& B: & $\begin{array}{c}\text { Kuraray } \\
\text { Medical } \\
\text { Inc., Japan }\end{array}$ & 51198 \\
\hline $\begin{array}{l}\text { Paste A: Silanized silica, colloidal silica, bisphenol A } \\
\text { polyethoxy dimethacrylate, 10-methacryloyloxydecil } \\
\text { dihydrogen phosphate, hydrophobic and hydrophilic } \\
\text { dimethacrylate, benzoyl peroxide and camphorquinone; } \\
\text { Paste B: Silanized barium glass, silanized titanium oxide, } \\
\text { sodium fluoride, colloidal silica, bisphenol A polyethoxy } \\
\text { dimethacrylate, hydrophobic dimethacrylate, hydrophilic } \\
\text { dimethacrylate, } \\
\text { n,n'-diethanol-p-toluidine, sodium sulphinate 2,4,6- } \\
\text { triisopropyl benzene. } \\
\text { Oxiguard: polyethylene glycol, glycerin, sodium benzene } \\
\text { sulphinate, n,n'-diethanol p-toluidine. }\end{array}$ & $\begin{array}{c}\text { ED Primer A: 2- } \\
\text { hydroxyethyl methacrylate, } \\
\text { 10-methacryloyloxydecil } \\
\text { dihydrogen phosphate, N-metha- } \\
\text { cryloyl-5-aminosalicylic acid, } \\
\text { n,n'-diethanol -p-toluidine and } \\
\text { water; ED Primer B: N-metha- } \\
\text { cryloyl- 5-aminosalicylic acid, } \\
\text { sodium benzene sulphinate, } \\
\text { n,n'-diethanol p-toluidine and } \\
\text { water. }\end{array}$ & & \\
\hline RELYX U100: & Not required. & $\begin{array}{c}\text { 3M ESPE, } \\
\text { USA }\end{array}$ & 287269 \\
\hline $\begin{array}{c}\text { Base paste: glass fiber, phosphoric acid esters } \\
\text { methacrylate, triethyleneglycol dimethacrylate, silica } \\
\text { treated with silane and sodium persulphate. Catalyst } \\
\text { paste: glass fiber, substitute dimethacrylate silica treated } \\
\text { with silane, p-toluenesulphate sodium and calcium } \\
\text { hydroxide. }\end{array}$ & & & \\
\hline
\end{tabular}

* Source: manufacturers' website

Figure 3- Cementation procedures

\begin{tabular}{|c|c|c|}
\hline Cement & Adhesive & Procedures \\
\hline Panavia F 2.0 & ED primer $\mathrm{A}$ and $\mathrm{B}$ & $\begin{array}{l}\text { Adhesive application (1 drop ED primer A + } 1 \text { drop ED primer B) for } 30 \mathrm{~s} \text {. Excess } \\
\text { removed with absorbent paper tips, air jet for } 10 \mathrm{~s} \text {. Paste A+ B manipulated for } \\
20 \mathrm{~s} \text {, applied to post, and post placed in the canal. Excess cement removed with } \\
\text { microbrush. Group A1: Oxiguard }{ }^{\circledR} \text { applied to exposed cement margins and removed } \\
\text { after } 3 \text { min with water spray; Group B1: Oxiguard }{ }^{\circledR} \text { applied as in the group A1 followed } \\
\text { by immediate light activation for } 20 \mathrm{~s} \text {; Group } \mathrm{C} 1: 20 \mathrm{~s} \text { light activation } 5 \text { minutes after } \\
\text { removal of Oxiguard. }\end{array}$ \\
\hline U100 & Not required & $\begin{array}{l}\text { The pastes were dispensed on a mixing pad from the Clicker and hand mixed for } 30 \\
\text { s. The cement was applied directly to the post that was inserted in the canal, excess } \\
\text { cement removed with microbrush. Group A1: No light activation after excess cement } \\
\text { removed; Group B1: Excess cement removed followed by immediate light activation } \\
\text { for } 20 \mathrm{~s} \text {; Group C1: Delayed light activation for } 5 \text { minutes after excess cement was } \\
\text { removed. }\end{array}$ \\
\hline
\end{tabular}

Where " $P$ " is the load (kgf); " $A$ " is the impression area $\left(\mathrm{mm}^{2}\right)$; "L" is the impression length $(\mathrm{mm}) ; \mathrm{C}_{\mathrm{p}}$ is the indenter correction factor. The measurements were averaged by thirds and the results $(\mathrm{KHN})$ were calculated for the thirds and groups.

\section{Statistical analysis}

The data was analyzed by separate three-way ANOVA testing applied to each cement and the individual differences were investigated by the Tukey's post-hoc test. The analysis investigated the influence of the curing mode, root location (thirds) and storage time. The significance level was set for all analysis at $\alpha=0.05$. 
Table 1- Knoop hardness number (KHN) standard deviation for Panavia 2F cement according to conditions tested

\begin{tabular}{ccccc}
\hline GROUPS/ CURING PROTOCOL & STORAGE & CERVICAL & MIDDLE & APICAL \\
\hline A1/ NO LIGHT ACTIVATION & 7 days & $41.2(3.38)^{\mathrm{Aa}}$ & $38.1(1.74)^{\mathrm{ABa}}$ & $35.6(1.73)^{\mathrm{Ba}}$ \\
A2/ NO LIGHT ACTIVATION & 3 months & $37.1(1.38)^{\mathrm{Ba}}$ & $35.0(0.74)^{\mathrm{ABa}}$ & $34.1(2.37)^{\mathrm{Aa}}$ \\
B1/ LIGHT ACTIVATION IMMEDIATELY & 7 days & $75.2(4.84)^{\mathrm{Ab} *}$ & $60.3(6.76)^{\mathrm{Bb}}$ & $48,9(3,33)^{\mathrm{Cb}}$ \\
B2/ LIGHT ACTIVATION IMMEDIATELY & 3 months & $63.0(2.17)^{\mathrm{Ab}}$ & $55.9(2.10)^{\mathrm{Bb}}$ & $48.5(1.62)^{\mathrm{Cb}}$ \\
\hline C1/ LIGHT ACTIVATION DELAYED & 7 days & $70.2(1.93)^{\mathrm{Bb} *}$ & $61.0(4.48)^{\mathrm{Ab} *}$ & $56.4(7.51)^{\mathrm{Ac} *}$ \\
C2/ LIGHT ACTIVATION DELAYED & 3 months & $56.9(1.21)^{\mathrm{Bb}}$ & $51.2(1.81)^{\mathrm{Ab}}$ & $48.2(3.00)^{\mathrm{Ab}}$ \\
\hline
\end{tabular}

* indicates significant differences between storage periods for the same group (subgroups 1 and 2).

Identical capital letters indicate no significant differences among thirds for the same curing protocol ( $p>.05)$.

Identical lower cases indicate no significant differences among curing protocols within each third ( $p>.05)$.

Table 2- Knoop hardness number (KHN) standard deviation for U100 cement according to conditions tested

\begin{tabular}{ccccc}
\hline GROUPS/ CURING PROTOCOL & STORAGE & CERVICAL & MIDDLE & APICAL \\
\hline A1/ NO LIGHT ACTIVATION & 7 days & $59.4(4.32)^{\mathrm{Aa}}$ & $52.1(3.00)^{\mathrm{Ba}}$ & $50.2(4.13)^{\mathrm{Ba}}$ \\
A2/ NO LIGHT ACTIVATION & 3 months & $52.3(2.00)^{\mathrm{Aa}}$ & $52.1(3.01)^{\mathrm{Aa}}$ & $51.0(1.48)^{\mathrm{Aa}}$ \\
B1/ LIGHT ACTIVATION IMMEDIATELY & 7 days & $62.4(6.83)^{\mathrm{Aa}}$ & $53.9(4.74)^{\mathrm{Ba}}$ & $49.0(2.20)^{\mathrm{Ba}}$ \\
B2/ LIGHT ACTIVATION IMMEDIATELY & 3 months & $58.8(2.34)^{\mathrm{Ab}}$ & $55.19(1.42)^{\mathrm{Ba}}$ & $55,7(3,17)^{\mathrm{Ba}}$ \\
C1/ LIGHT ACTIVATION DELAYED & 7 days & $62.4(6.66)^{\mathrm{Aa}}$ & $53.6(2.00)^{\mathrm{Ba}}$ & $51.5(2.18)^{\mathrm{Ba}}$ \\
C2/ LIGHT ACTIVATION DELAYED & 3 months & $59.0(2.04)^{\mathrm{Ab}}$ & $57.0(2.04)^{\mathrm{ABa}}$ & $54.9(1.05)^{\mathrm{Ba}}$ \\
\hline
\end{tabular}

* indicates significant differences between storage periods for the same group (subgroups 1 and 2).

Identical capital letters indicate no significant differences among thirds for the same curing protocol ( $p>.05)$.

Identical lower cases indicate no significant differences among curing protocols within each third ( $p>.05)$.

\section{RESULTS}

For the Panavia (Table 1 ), the hardness was affected by the curing protocol $(p=0.001 ; F=218.7)$, thirds $(p=0.0001)$ and storage $(p=0.0001)$. Significant interactions were also found between the storage vs. curing protocol $(p=0.013)$, storage $v s$. thirds $(p=0.0001)$, and the curing protocol vs. thirds $(p=0.0001)$. No significant interaction were found between the storage, curing protocol and thirds $(p=0.093)$. When no light activation was provided (Group $A)$, the hardness was uniform along the root $(p>.05)$ and significantly lower between the cervical and apical third $(p<.05)$. When light was provided (Groups B and $C$ ), the hardness was significantly higher at the cervical cuff $(p<.05)$ and decreased significantly towards the apical third $(p<.05)$ except in group $C 1$ that did not show a difference between the middle and apical thirds. At the apical third, delaying light activation for 5 min (C) resulted in significantly higher hardness than both immediate light activation (B) and chemical activation $(A)(p<.05)$.

Water storage for 3 months caused reductions in the hardness regardless of the thirds and curing modes. When comparing the storage periods, the results were not significant when no light was provided (Group A1 vs. A2, p>.05), but were significant when light was provided at the cervical cuff (Group B1 vs. B2), especially for the delayed activated (Group C1 vs. C2), in which significant reductions were observed in all three thirds $(p<.05)$.

For the U100 cement (Table 2 ) the effects of the curing protocol $(p=0.018 ; F=4.74)$ and region of the root $(p=0.0001 ; F=60.3)$ were significant. No significant differences were found between the storage periods $(p=0.878 ; F=0.02)$. Significant interactions were found for the storage $v s$. the thirds $(p=0.0001 ; F=21.6)$. Higher, but not significant hardness was observed when light was provided. This was only evident at the cervical cuff at the 7-day period.

Water storage did not cause changes in the hardness for most of the testing conditions, except for the immediate light activation (Group B1 vs B2) at the apical third $(p<.05)$.

\section{DISCUSSION}

The results showed that light activation always resulted in higher hardness than no light activation. This was more evident for the Panavia than the U100, regardless of the thirds and storage. These results are in agreement with the literature and suggest that dual cure cements should be light activated in order to maximize their properties ${ }^{12,30}$. 
Since dual cure cements have two polymerization routes, it is expected that chemical polymerization ensures curing in the regions most distant from the light source ${ }^{8}$. Although these two routes are present in the dual cure cement, chemical polymerization will not activate the photosensitive portion of the cement if the light exposure is insufficient, as may occur in the apical portion of intra-radicular luted posts $^{24}$. Ideally, the two polymerization routes should occur simultaneously and independently. However, a concern has been raised that as light activation promotes rapid stiffening of the polymer chains, the development of the chemical reaction is affected, thus altering the physical properties of the material ${ }^{8}$. The question about whether light activation would harm the chemical reaction of some dual cure cements ${ }^{24}$ led some authors to suggest delaying the light activation for a few minutes after mixing and luting ${ }^{23}$. The results of this study did not support this aspect for the two cements evaluated. The significant reduction in the hardness of the Panavia cement in the middle and apical thirds shows the effect of the attenuation of the light intensity as a result of the distance from the light source and transmission through the cement ${ }^{18,28}$, which progressively reduces the rate of polymerization. In this study, both cements presented higher hardness when light activation was provided (Groups B and C), and there was no indication that light activation compromised the hardness in any situation investigated. On the contrary, the higher hardness observed for the cervical third suggests that the properties of both cements are positively influenced by light exposure.

Storage in water for 3 months caused significant reductions in the hardness in most groups, irrespective of the activation mode and region. This was more evident for the Panavia than for the U100. The effect of water on the polymeric network is described as plasticizing and it promotes the reduction in hardness due to the separation of the polymeric chains by molecules that do not form primary links with them, but only occupy a space between them. Thus, the polymer is not dissolved, but intumesces in contact with the solvent that promotes a greater attraction between the molecules of the solvent and the components of the chains that exceed the forces of attraction between the polymer chains ${ }^{7}$. Consequently, there is an increase in volume of the polymeric network and a potential effect of plasticization resulting from less interaction between the chains ${ }^{7,16}$. The results for the U100 suggest that the hardness was dependent on the contact and reaction of the cement with the dental structures, which occurred inside the canal. The mechanism of self-adhesion to the dental structures occurs due to the presence of phosphorylated methacrylate radicals ${ }^{1}$, which are neutralized by the substrate when in contact with the dentin while the material is polymerized. In this material, the water formed during the initial reaction of the phosphorylated methacrylates with the apatite and basic load particles is reused in the reaction with excess acids, which result in the substitution of hydrophilic properties before setting by the hydrophobic properties after setting. This suggests a reduction of sensitivity of the material to humidity, and a consequent reduction of solubility in the oral medium ${ }^{1}$. Therefore, this cement was shown to be less critical in the presence of humidity probably because of being dimensionally stable and because the water produced in the chemical reaction is consumed in other reactions of the cement itself ${ }^{26}$.

Although there are several difficulties in reproducing the oral conditions in in vitro studies, especially with regard to humidity, the results of this experiment show the existent obstacles to achieve an adequate degree of conversion in the intra-radicular environment. When hardness tests are used as an indirect measurement of the degree of conversion of composites, it is important to consider the different chemical compositions of the evaluated brands, bearing in mind that these influence the cross-link density formed during polymerization and consequently, the mechanical properties of the material ${ }^{15}$. The attenuation and dispersion of the halogen light resulting from material thickness, distance from the surface and size and amount of load produces a gradual reduction in polymerization ${ }^{17}$. Therefore, the adequate degree of conversion of a luting agent is very important for the longevity of the restoration. Some resin cements, such as the Panavia F $2.0^{\circledR}$, are materials that are dependent on the light activation of polymerization to reach adequate properties $5,22,25$. The polymerization potential of dual cure resin cements varies widely among products ${ }^{26,29}$ and this variation was also confirmed in this study.

The results obtained in the hardness tests are in agreement with the concepts generally accepted in the literature, which is that all dual cure cements should be light activated to reach their maximum properties $6,14,20,30$. Generally, the simplification of steps in the adhesive system and the polymerization reaction of adhesives and resin cements have a direct effect on the adhesive post/dentin substrate interface ${ }^{2}$. The results of this study indicated that the delay of light activation was not an efficient procedure. Isolated cases of improvement or harm were observed, but no trend could be established. Thus, delaying light activation of the cement is not justifiable as a protocol for the dual cure cements evaluated in this study. In general, dual cure cements require light activation to reach their adequate physical and mechanical properties so 
that the restorations can bear the stresses that are produced at the restoration/cement/tooth interface, especially in the early post-cementation periods. The professional must be aware that these cements do not reach a degree of maximum polymerization in areas distant from the light source. However, it remains unknown how this shortcoming manifests clinically.

\section{CONCLUSIONS}

Based on the results obtained, it could be concluded that:

1- The light activation with halogen light promoted a significant increase in the hardness for the Panavia cement;

2- Storage in water for three months reduced the micro-hardness values for most groups, and the U100 cement showed less variation in the results when compared with the Panavia;

3- Most cervical thirds showed the highest hardness for both cements.

\section{ACKNOWLEDGEMENTS}

This study was funded by FAPESP \# 07/02612-2, CNPq \# 307510/2010-7 and Capes, Brazil.

\section{REFERENCES}

1- 3M ESPE. Rely X U100 self-adhesive universal resin cement. USA: 3M ESPE; 2008.

2- Abou-Id LR, Morgan LF, Silva GA, Poletto LT, Lanza LD, Albuquerque RC. Ultrastructural evaluation of the hybrid layer after cementation of fiber posts using adhesive systems with different curing modes. Braz Dent J. 2012;23:116-21.

3- Acquaviva PA, Cerutti F, Adami G, Gagliani M, Ferrari M, Gherlone $E$, et al. Degree of conversion of three composite materials employed in the adhesive cementation of indirect restorations: a micro-Raman analysis. J Dent. 2009;37:610-5.

4- Aksornmuang J, Nakajima M, Foxton RM, Tagami J. Mechanical properties and bond strength of dual-cure resin composites to root canal dentin. Dent Mater. 2007;23:226-34.

5- Arrais CA, Giannini M, Rueggeberg FA, Pashley DH. Microtensile bond strength of dual-polymerizing cementing systems to dentin using different polymerizing modes. J Prosthet Dent. 2007;97:99106.

6- Arrais CA, Rueggeberg FA, Waller JL, Goes MF, Giannini M. Effect of curing mode on the polymerization characteristics of dual-cured resin cement systems. J Dent. 2008;36:418-26.

7- Asmussen E. Softening of BISGMA-based polymers by ethanol and by organic acids of plaque. Scand J Dent Res. 1984;92:257-61. 8- Asmussen E, Peutzfeldt A. Polymer structure of a light-cured resin composite in relation to the distance from the surface. Eur J Oral Sci. 2003;111:277-9.

9- Bonfante EA, Pegoraro LF, Goes MF, Carvalho RM. SEM observation of the bond integrity of fiber-reinforced composite posts cemented into root canals. Dent Mater. 2008;24:483-91.
10- Burke FJ. Trends in Indirect Dentistry: conclusions. Dent Update. 2005;32:251-4.

11- Cadenaro M, Navarra CO, Antoniolli F, Mazzoni A, Di Lenarda $R$, Rueggeberg $F A$, et al. The effect of curing mode on extent of polymerization and micro-hardness of dual-cured, self-adhesive resin cements. Am J Dent. 2010;23:14-8.

12- Ceballos L, Garrido MA, Fuentes V, Rodríguez J. Mechanical characterization of resin cements used for luting fiber posts by nanoindentation. Dent Mater. 2007;23:100-5.

13- Cekic-Nagas I, Ergun G. Effect of different light curing methods on mechanical and physical properties of resin-cements polymerized through ceramic discs. J Appl Oral Sci. 2011;19:40312.

14- El-Badrawy WA, El-Mowafy OM. Chemical versus dual curing of resin inlay cements. J Prosthet Dent. 1995;73:515-24.

15- Ferracane JL. Correlation between hardness and degree of conversion during the setting reaction of unfilled dental restorative resins. Dent Mater. 1985;1:11-4.

16- Ferracane JL. Hygroscopic and hydrolytic effects in dental polymer networks. Dent Mater. 2006;22:211-22.

17- Ferrari M, Vichi A, Grandini S, Goracci C. Efficiency of a self-curing adhesive-resin cement system on luting glass-fiber posts into root canals: an SEM investigation. Int J Prosthodont. 2001; 14:543-9.

18- Goracci C, Corciolani G, Vichi A, Ferrari M. Light-transmitting ability of marketed fiber posts. J Dent Res. 2008;87:1122-6.

19- Halvorson RH, Erickson RL, Davidson CL. Energy dependent polymerization of resin-based composite. Dent Mater. 2002;18:4639.

20- Hofmann N, Papsthart G, Hugo B, Klaiber B. Comparison of photo-activation versus chemical or dual-curing of resin-based luting cements regarding flexural strength, modulus and surface hardness. J Oral Rehabil. 2001;28:1022-8.

21- Koupis NS, Vercruysse CW, Marks LA, Martens LC, Verbeeck RM. Curing depth of (polyacid-modified) composite resins determined by scraping and a penetrometer. Dent Mater. 2004;20:908-14.

22- Lee IB, An W, Chang J, Um CM. Influence of ceramic thickness and curing mode on the polymerization shrinkage kinetics of dualcured resin cements. Dent Mater. 2008;24:1141-7.

23- Lovell LG, Newman SM, Bowman CN. The effects of light intensity, temperature, and comonomer composition on the polymerization behavior of dimethacrylate dental resins. J Dent Res. 1999;78:1469-76.

24- Miller M. Do we really need dual-cure cements? Gen Dent. 2004;52:494-5.

25- Moraes RR, Faria-e-Silva AL, Ogliari FA, Correr-Sobrinho L, Demarco FF, Piva E. Impact of immediate and delayed light activation on self-polymerization of dual-cured dental resin luting agents. Acta Biomat. 2009;5:2095-100.

26- Pedreira AP, Pegoraro LF, Góes MF, Pegoraro TA, Carvalho RM. Micro-hardness of resin cements in the intra-radicular environment: effects of water storage and softening treatment. Dent Mater. 2009;25:868-76.

27- Pegoraro TA, Silva NR, Carvalho RM. Cements for use in esthetic dentistry. Dent Clin North Am. 2007;51:453-71.

28- Pereira SG, Fulgêncio R, Nunes TG, Toledano M, Osorio R, Carvalho RM. Effect of curing protocol on the polymerization of dual-cured resin cements. Dent Mater. 2010;26:710-8.

29- Peutzfeldt A. Dual-cure resin cements: in vitro wear and effect of quantity of remaining double bonds, filler volume, and light curing. Acta Odontol Scand. 1995;53:29-34.

30- Rueggeberg FA, Caughman WF. The influence of light exposure on polymerization of dual-cure resin cements. Oper Dent. $1993 ; 18: 48-55$. 